\title{
PUERTOS ATLÁNTICOS Y MEDITERRÁNEOS EN TIEMPOS DE TRAJANO*
}

\author{
ATLANTIC AND MEDITERRANEAN PORTS \\ IN THE TIME OF TRAJAN
}

\author{
Javier Bermejo Meléndez \\ Universidad de Huelva \\ javier.bermejo@dhis1.uhu.es \\ ORCID: 0000-0002-1905-8398 \\ Juan M. Campos Carrasco \\ Universidad de Huelva \\ campos@uhu.es \\ ORCID: 000-0002-4930-2515
}

DOI: $10.1387 /$ veleia.19436

\begin{abstract}
Resumen: Con el ascenso de Trajano al poder en las postrimerías del s. I d.C. el estado conocerá un profundo proceso de reformas tendentes a mejorar la delicada situación administrativa, y especialmente financiera, heredadas del último emperador flavio. En este contexto las medidas puestas en marcha por el emperador hispano tendentes a reforzar el aparato de suministros estatales, la annona, hacia los mercados urbanos y el limes del imperio supondrá el desarrollo de una importante provincialización económica, así como un aumento del intervencionismo estatal. En línea con esta argumentación recogemos en el siguiente trabajo una docena de enclaves portuarios que jalonaron las principales rutas de abastecimiento y en los que se aprecia un importante desarrollo de su topografía, con nuevos espacios de almacenamientos, aumento del volumen de mercancías, etc. al socaire de esta nueva etapa comercial.
\end{abstract}

Palabras clave: puertos, stationes, Ostia, portus Traiani, annona.

Abstract: With the rise of Trajan to power at the end of 1 st. century AD the state will see a profound process of reforms tending to improve the delicate administrative situation, and especially the financial one inherited from the last flavian prince. In this context, the measures implemented by the Spanish emperor tending to reinforce the apparatus of the state supplies, the annona, towards the urban markets and the limes of the empire will turn out in the development of an important economic depend on provinces as well as an increase of the

* El presente trabajo se enmarca dentro de las actividades de los proyectos de investigación «Del Atlántico al Tirreno. Los puertos atlánticos béticos y lusitanos y su relación comercial con Ostia Antica» DeAtlantir I y II (HAR2014-58326-P; HAR2017-89154-P) pertene- cientes al Plan Nacional de I+D+I y «Ciudades Romanas de la Bética. CORPVS VRBIVM BAETICARVM" (CVB) (HUM 2062) correspondiente a la convocatoria de Proyectos de Excelencia del Plan Andaluz de Investigación. 
state interventionism. Following this line of argumentation, I gather in the following paper a list of a dozen harbour zones that marked the main supply routes, and in which it can be appreciated an important development of the topography thanks to the new storage spaces, the increase in the volume of goods, etc., at the end of this new commercial stage.

Keywords: ports, stationes, Ostia, portus Traiani, annona.

Recibido: 22/3/2018

Informado: $16 / 4 / 2018$

Definitivo: $13 / 5 / 2018$

LAS MEDIDAS POLÍTICAS Y ECONÓMICAS DE TRAJANO, HACIA UNA MAYOR INTERVENCIÓN ESTATAL

Actualmente, y espoleado por el desarrollo de diversos proyectos de investigación centrados en la temática portuaria del mundo antiguo, se está produciendo un importante avance en el conocimiento de numerosos enclaves fluviales y marítimos, tanto atlánticos como mediterráneos, que jugaron un importante papel en el desarrollo y el abastecimiento de toda una serie de rutas comerciales indispensables, en algunos casos, para el sostenimiento de buena parte del esquema económico y político del imperio (Keay et al. 2005; 2012; Sanchez \& Jézúgou 2011; Campos \& Bermejo 2017). Lejos de modas historiográficas o investigadoras, el impulso del que viene siendo objeto la temática portuaria en el mundo antiguo pone de relieve la importancia que determinados enclaves jugaron en la conformación y devenir del imperio, con el establecimiento de todo un sistema de redes orientadas a Roma y otros puntos estratégicos de las costas mediterráneas.

La adopción por parte del anciano Nerva, en octubre de 97, de M. Ulpio Trajano y su posterior ascenso al solio imperial marcarán el inicio de un nuevo periodo para el sistema político creado por Augusto algo más de un siglo antes (Eck 2002, 211 y ss.). En el marco de este planteamiento las medidas desarrolladas por el Optimus Princeps supusieron en los inicios del s. II d.C. un cambio significativo con respecto a tiempos precedentes, al garantizar el abastecimiento de la Urbs y sus mercados, lo que supondrá un nuevo periodo de esplendor comercial y económico. Los años siguientes de su imperio suponen una nueva orientación en todas las parcelas del estado, en las que los aspectos económicos y comerciales, así como el abastecimiento de productos para los mercados urbanos a través de la annona, vitales para el sostenimiento del imperio, serán objeto de profundas modificaciones y cambios (Chic 2000, 79). En este contexto de reformas, la actividad legislativa del periodo trajaneo parece encaminada a consolidar un conjunto de medidas de refuerzo en materia intervencionista. No en vano el abastecimiento de la Urbs y el mantenimiento de los ejércitos en los límites del imperio son dos pilares fundamentales hacia los que se dirigen buena parte de las disposiciones del momento. En los inicios del s. II d.C. se acentúa de manera exponencial el intervencionismo estatal en los sectores económicos; para ello una de las instituciones a las que mayor atención prestarán las medidas desarrolladas por el Optimus Princeps será la annona. En esta coyuntura se promulgan distintos edictos que permiten que aquellos particulares que sirvan a los intereses económicos del estado a través de aquella, quedarán exentos de cargas fiscales municipales (Chic 1999, 260; 2000, 83; Remesal 2011, 226, 227), lo que marcará el devenir posterior de los ordenamientos de las ciudades del Imperio. La llegada de Trajano coincide con una profunda crisis económica en cuyo marco las políticas expansionistas y territoriales, con la inyección del oro dácico y el acompañamiento de un programa de colonizaciones, suponen, según Montero Díaz, una evocación del esplendor de un estado en plena prosperidad. La aspiración de fortalecer el mecanismo estatal, con importantes problemas políticos y económicos heredados de la etapa flavia, subyacen 
en el pensamiento político de Trajano; su imperio se traduce en una movilización racionalizada a gran escala de todos los recursos disponibles para mantener el concepto de un estado universal (Montero 1955, 22, 23).

En el diseño de estas políticas, por tanto, las acciones militares de conquista y expansión territorial serán fundamentales a la hora de conseguir incorporar nuevos recursos económicos, metales (Dacia) y accesos a rutas de Oriente (creación de Arabia y conquista del Imperio Parto), todo ello con la intención de afianzar la presencia de Roma en antiguas áreas a través de un intenso programa de reajustes territoriales que cristalizaría en un proceso de fundaciones y promociones coloniales y municipales en las provincias de Germania, Dacia, Tracia, Africa y Arabia, con lo que se puede afirmar, sin ningún género de dudas, que con la obra de Trajano se asiste al último gran impulso colonizador del imperio romano (Bermejo, Robles \& Campos 2013, 111).

El inicio de esta etapa y las reformas que dieron origen a la misma hay que buscarlas, pues, en las acciones de Trajano, en las disposiciones legales que se ponen en marcha bajo su imperio y que tenía a los domini navium en el centro de las mismas ${ }^{1}$. De cara al abastecimiento de la annona, muy probablemente Trajano fue el autor intelectual de la creación de los corpora naviculariorum cuyos miembros debían de emplear al menos la mitad de sus propiedades en la construcción o mantenimiento de buques para el transporte de la annona de Roma. La interpretación de Sirks, en su ya clásico trabajo Food for Rome, es que Trajano promulgó el edicto para estimular la construcción naval y asegurar de este modo el transporte de grano tan necesario para las frumentationes y para mantener a bajo precio otros productos alimenticios básicos o esenciales. En este marco es donde se produce la creación, bien bajo los auspicios del propio emperador o bien bajo el senado, de otros corpora tales como lenuncularii, caudicarii, pistores, negotiatores, todos ellos vinculados directamente con la annona y bajo el control directo del emperador (Sirk 1991, 74 y ss.) y que verán su trasunto a otros enclaves comerciales estratégicos provinciales, como demuestra el ambiente epigráfico del portus hispalensis (González 2013, 64).

La puesta en marcha de todas estas políticas debieron coincidir en los inicios del siglo con la construcción de su Portus Traiani Felicis en Ostia, un enclave estratégico iniciado por Claudio, pero que conocerá ahora una importante reforma con la construcción de una dársena interior, con mayor capacidad de carga/descarga y un sistema de canales interiores que conectaban Portus con el Tíber de cara a conseguir una mayor operatividad en el transporte de mercancías a Roma (Keay \& Millet 2005, 281 y ss.). Como ya indicara Rickman, el proyecto y construcción del puerto de Trajano marcó un serio intento por centralizar el comercio de la capital, particularmente su suministro de grano, en Ostia y en Portus (fig. 1). El puerto interior garantizó seguridad para una amplia variedad de envíos, al aumentar de manera exponencial los graneros y almacenes disponibles en la boca del Tíber. Al mismo tiempo en Roma se reforman las instalaciones del emporium, del distrito de portus tiberinus de forma que son sustancialmente mejorados. Abandonada la antigua idea de canales interiores, Roma marcó su independencia con respecto a los puertos de Campania a tra-

${ }^{1}$ La categoría de domini navium fue creada por Claudio en 51 d.C.; personas que habían construido barcos y habían permitido que llevaran grano a Roma fueron premiadas con diversas concesiones en función de su estatus o posición. Esos buques habían sido destinados a fines comerciales, pero también estuvieron destinados al transporte de grano. Nerón eximió a estos buques del tributum, si eran propiedad de los comer- ciantes. Posteriormente Trajano añadió la vacatio $m u$ neris publici para premiar a los domini navium; esto, sin embargo, no incluiría una excepción para los que ejercían la tutela del navío. Los buques que no estaban a disposición de la annona de Roma, pudieron haber estado bajo la supervisión de oficiales del gobierno (curatores navium marinarum) (Sirk 1991, 80). 
vés de un importante sistema con la construcción, por parte de Trajano, de dos puertos cercanos; uno al norte del Tíber en Centucellae y otro en Terracina, ambos satélites del gran puerto trajaneo (Rickman 1991, 109).

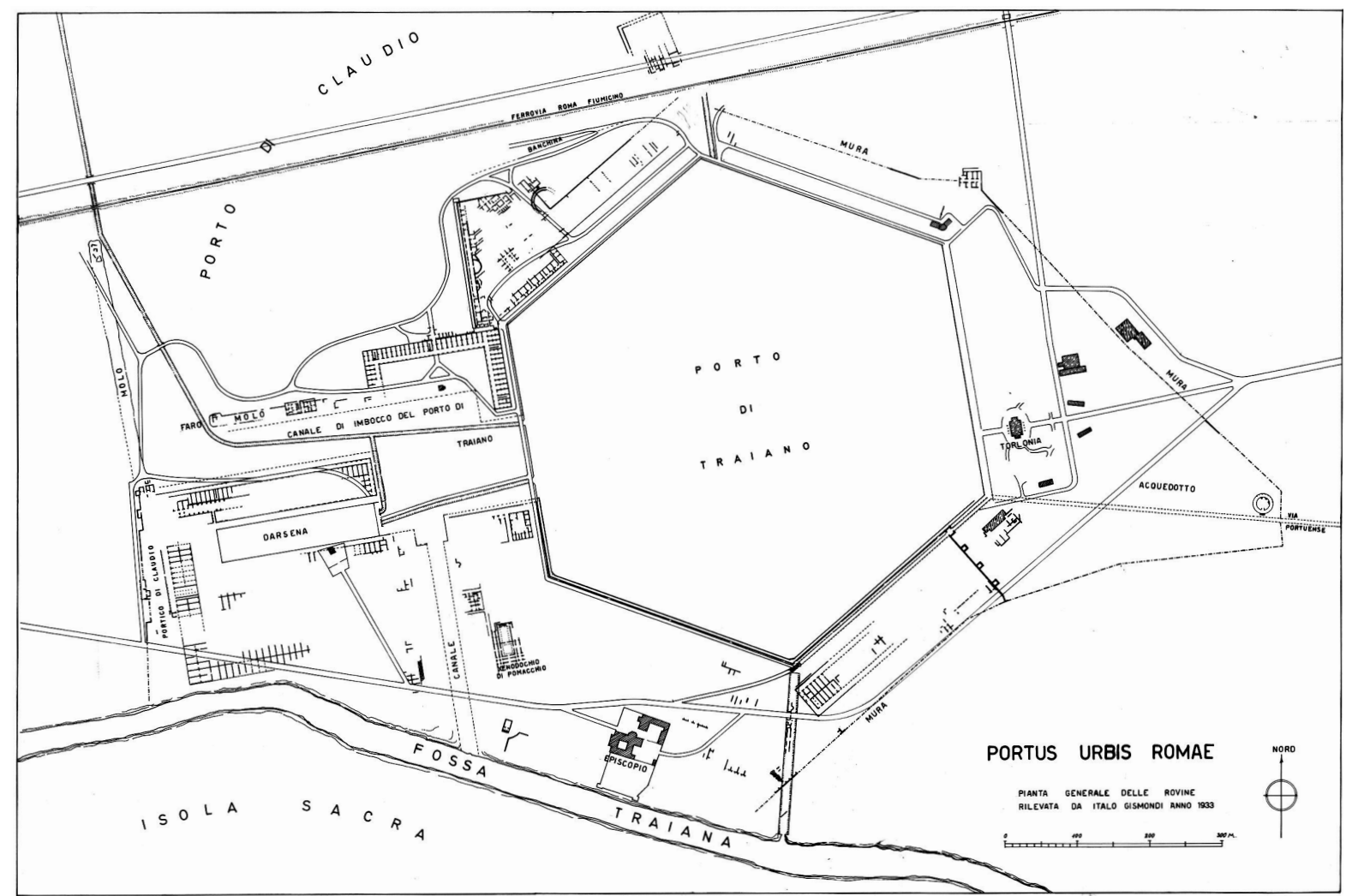

Figura I. Planta general del puerto de Trajano (plano de I. Gismondi. Archivo de la Soprintendenza Speciale per il Coloseo, il MNR e l'area Archeologica di Roma C/Cass. 4/1/num 2637).

Asistimos por tanto a un programa dirigido de manera global a superar la situación de crisis económica que desde el periodo domicianeo viene sufriendo el estado; un intento por dotar de una nueva proyección al imperio en este contexto de políticas centralizadoras, control de monopolios de productos estatales (metalla, aceite, etc.) que llevará una reorganización del comercio, los agentes implicados y cómo no, por efecto de todo ello, un importante despegue de los principales puertos atlánticos y mediterráneos que jugaron un papel destacado como puntos de recalada en la red de rutas comerciales.

\section{LOS PUERTOS ATLÁNTICOS Y MEDITERRÁNEOS, TESTIGOS DE UN NUEVO PERIODO COMERCIAL}

$\mathrm{Al}$ socaire de las nuevas medidas puestas en marcha a fines del s. I y comienzos del il d.C., podemos intuir una época de febril actividad económica y comercial que supondrá el desarrollo de 
importantes áreas portuarias de las principales ciudades que jalonaban el tráfico comercial de determinados productos. Las investigaciones que desde hace algunos años se vienen desarrollando en las ciudades portuarias atlánticas, fluviales y marítimas, de Baetica y Lusitania en el marco del proyecto DEATLANTIR (Campos \& Bermejo 2017) revelan una importante fase de desarrollo en la topografía portuaria de las mismas, la aparición de distintas tipologías arquitectónicas (horrea, stationes, etc.), así como un importante floruit comercial del cual es testigo el importante volumen de mercancías trasegadas, tanto exportadas como importadas, que se encuentran insertas en los circuitos comerciales. En el contexto de dicho proyecto, perteneciente al Plan Nacional de I+D+i, se han podido iniciar interesantes líneas de estudio, así como profundizar en otras tantas existentes, que suponen a día de hoy el grueso del conocimiento existente para estos puertos atlánticos. En el marco del Mediterráneo occidental, del mismo modo, recientes investigaciones llevadas a cabo en los puertos y stationes de la Gallia Narbonensis, Narbo, Areles y Massalia, entre otros, ponen de relieve la significación de estos distritos marítimos y su evolución diacrónica (Sanchez \& Jézéguo 2011). De manera paralela y como una investigación de referencia en esta temática, las actividades desarrolladas en el seno del proyecto Portus, dirigido por el Prof. Dr. S. Keay, suponen una parte importante del conocimiento actual sobre numerosos enclaves portuarios mediterráneos. De entre ellos destaca el área de los puertos imperiales y su complejo sistema de canales, dársenas, etc. cuya investigación los ha posicionado como un referente de primer orden en la investigación de puertos antiguos (Keay et al. 2005; 2012).

\section{LOS PUERTOS ATLÁNTICOS}

El denominado arco atlántico del suroeste peninsular hispano supone un área de especial interés a la hora de comprender las políticas económicas desarrolladas en los comienzos del imperio de Trajano; a través de estos distritos marítimos se exportaron un conjunto de productos jerarquizado en dos sistemas o circuitos comerciales claramente diferenciados, por un lado un comercio libre en el que participaban empresas y particulares y, por otro, un comercio administrado o fiscalizado (annonario) directamente desde el poder imperial por medio de un sistema de procuratelas y funcionarios imperiales de segundo rango que orientaron la provincialización económica de estos puertos y por ende de sus territorios. La investigación actual refleja un importante nivel de desarrollo comercial entre las correspondientes áreas geográficas del atlántico sudhispánico, el mediterráneo occidental y los puertos imperiales, focos de atracción de las principales mercancías y productos que se exportaban desde los primeros (Campos \& Bermejo 2017, 15, 16). De manera general para los puertos de este amplio litoral atlántico, la investigación desarrollada en los últimos años pone de relieve la importancia de su papel en la configuración de las redes de abastecimientos mediterráneas y especialmente itálicas con los distritos portuarios de Roma a la cabeza.

En un análisis más detallado de estos enclaves portuarios del arco atlántico del suroeste, y de poniente a levante, Ossonoba es el gran puerto del sur de Lusitania. La ciudad sufrirá un importante desarrollo urbano a partir del estatuto de municipalidad flavio y un gran momento de expansión a partir de inicios del s. II d.C. En el actual largo de San Francisco se ubica el área nuclear del puerto, y próximo a él la zona pública monumental de la ciudad, como era tan frecuente en las ciudades romanas portuarias (Bernardes 2005; 2012). En estos momentos trajaneos, Ossonoba muestra una más que destacada actividad comercial vinculada a la Bética atlántica, lo que exigía abultados capitales y una intensa red de contactos, así como de infraestructuras portuarias, officinae, horrea, instalaciones para el personal, salinas, etc. Los inicios del s. II d.C. traen la consolidación y 
proyección comercial del enclave, conectado a través de Gades con los circuitos mediterráneos y especialmente tirrénicos; este panorama se verá incrementado a medida que avance esta centuria y especialmente en la siguiente, todo ello en un amplio sistema de áreas portuarias secundarias con centros exportadores como Quinta de Marim y Cerro da Villa, en donde se comprueba una importante fase de desarrollo en momentos tardoflavios e inicios del s. II d.C. (Bernardes 2017, 384 y ss.; Teichner 2017, 408, 422). Seguidamente Myrtilis, en el curso final del Anas, es otro de los puertos significativos en nuestro análisis. A día de hoy el periodo tardoantiguo supone el de mayor interés por la calidad y cantidad de datos que se conocen (Lopes 2017), sin embargo, para momentos altoimperiales se tiene localizada el área portuaria y, próximos a ella, interesantes depósitos anfóricos en los que destacan los materiales de finales del s. I y principios del II d.C., ánforas de aceite béticas acompañadas de algún numerario trajaneo. Todo ello muestra, junto con otros datos epigráficos, la promoción municipal del enclave, así como una importante actividad comercial y económica para inicios de la segunda centuria (Lopes 2014, 61, 62).

Ya en la Bética, puertos como Onoba Aestuaria muestran claros indicios en su topografía portuaria de destacados síntomas de desarrollo urbano, económico y comercial para momentos tardoflavios y primoantoninos (Campos 2011; Delgado 2016). La ubicación de dos amplias zonas portuarias, una de carácter industrial representada por talleres haliéuticos y otra destinada a actividades de control y administración se completan para estos momentos con la aparición de una posible statio metallorum, horrea, así como un edificio absidiado junto al faro, todo ello acompańado de un importante aumento del volumen de importaciones galas y africanas en el tránsito de estas centurias (Bermejo, Campos \& Rodríguez-Vidal 2017, 234, 235). Todos estos testimonios arqueológicos denotan las repercusiones que las medidas y disposiciones legales referentes al tráfico annonario, puestas en marcha en los primeros años del ascenso de Trajano, tuvieron para estos puertos atlánticos.

Junto con Onoba, Gades supone el otro gran puerto atlántico del suroeste. La investigación más reciente permite sentar numerosas premisas de trabajo en una morfología cada vez más clara del puerto gaditano y sus distritos portuarios secundarios al otro lado de la bahía desde momentos prerromanos e inmediatamente posteriores, con especial incidencia en su importante industria haliéutica (entre otros: Ponisch 1968; García \& Chaves 1991; Ruiz \& Pérez 1995; Bernal \& Lagóstena 2004; Sáez 2008; 2014; Sáez \& Díaz 2014; Niveau 2015; Sáez et al. 2017). Actualmente el conocimiento del urbanismo portuario de la Gades romana comienza a intuirse de manera cada vez más prometedora (Bernal \& Lara 2012), a la espera de estudios monográficos que a buen seguro aportarán nuevos datos e interpretaciones. Para momentos flavio-trajaneos se documentan en el entorno de la bahía significativas obras portuarias que dan testimonio de la actividad productiva para estos momentos del entorno del portus Gaditanus (Bernal 2012, 236; Bernal et al. 2005, 206-209).

Finalmente, Hispalis supone el enclave portuario más importante de esta área atlántica. la investigación de las últimas décadas y, especialmente, aquella más reciente ofrece interesantes datos para la comprensión de la morfología urbana de Colonia Romula Hispalis y su puerto marítimo-fluvial de manera diacrónica desde momentos republicanos hasta época tardoantigua (Campos 1990, 1993; Campos \& González 1987; González 2010; 2011; 2012; Cabrera 2016). En este amplio marco cronológico la imagen del puerto hispalense fue variando sustancialmente; sin embargo, para momentos del s. II podemos indicar que alcanzó un destacado papel al convertirse en la base de operaciones de la annona en la Provincia, de lo que dan testimonio no solo el importante ambiente epigráfico, con presencia de funcionarios imperiales y menciones de corporaciones (González 2017), sino, además, un conjunto de restos arqueológicos como diques, atraques de ribera, almacenes portuarios y una posible statio olearium. Para estos momentos de fines del s. I y 
comienzos del II d.C., el área portuaria se consolida en la zona meridional de la ciudad y en la orilla izquierda del río con el desarrollo de importantes obras de atraque sobre pilotajes de madera y de fábrica donde se instala un conjunto de almacenes, como demuestran los restos bajo el Patio de Banderas (García, Ordoñez \& Cabrera 2017, 278). Sin lugar a dudas, este momento de expansión del puerto hispalense, en el tránsito de centurias, está relacionado con el destacado papel que jugó en el contexto de abastecimiento de la annona y el desarrollo de un sistema administrativo de control y gestión de este servicio en el que las medidas desarrolladas por Trajano favorecerán al puerto hispalense.

\section{Los PUertos Del MediterRáneo ocCidental}

Desde estos puertos, con sus stationes o fondeaderos de apoyo, se iniciaban las principales rutas annonarias de abastecimiento para el estado, las cuales, en su camino hacia los mercados urbanos y otros puntos del limes, encontraban en las costas mediterráneas un conjunto de enclaves portuarios que, sin duda, también se vieron inmersos en el trasiego e intercambio de productos al socaire de un periodo económico claramente expansivo en los inicios de la segunda centuria. Prueba de ello son los resultados que las investigaciones ofrecen en los numerosos puertos que jalonaban estas rutas; para enclaves como Baelo Claudia, las recientes excavaciones del suburbium occidental demuestran un significativo crecimiento urbano y económico a comienzos del s. II d.C. desconocido hasta la fecha (Bernal et al. 2013, 178); más complejo en el estado actual de la investigación supone realizar algún tipo de precisión para este momento sobre las, cada vez mejor conocidas, estructuras portuarias (Bernal et al. 2017), aunque, si bien es cierto el tránsito a la segunda centuria supone un periodo de crecimiento y pudo tener su reflejo en la dotación de este tipo de infraestructuras.

De similar manera parece suceder en los enclaves marítimos de la costa malacitana, en donde al periodo de cambios jurídicos de la anterior etapa flavia le sucede, al menos durante la primera mitad del s. II d.C., un importante despegue o crecimiento de las villae maritimae de este litoral, con significativas áreas productivas y de representación en estos complejos. Tal proceso testimonia el desarrollo de importantes élites enriquecidas al amparo de la exportación de los productos pesqueros y sus derivados (Corrales 2008, 171), en conexión con los viajes annonarios que desde época de Trajano sufren importantes reajustes y cambios, como prueban determinados testimonios epigráficos de mediados del s. II d.C. ${ }^{2}$, en donde se nos muestra a un negotians salsarius y quinquenal del Corpus Negotiantium Malacitanorum realizando una dedicación al praefectus annonae en la propia ciudad de Roma; lo que pone de relieve la existencia de intereses y relaciones económicas de los salsamentarii béticos con la institución annonaria, más allá de los productos fiscalizados por la misma.

Ya dentro de la provincia Tarraconensis, Cartagho Nova supone uno de los principales puertos del contexto hispano mediterráneo desde momentos prerromanos con una importancia capital para la administración de Hispania y sus recursos meridionales desde época republicana, tal y como atestigua el desarrollo de su comercio, la presencia de negotiatores y un conjunto de estructuras portuarias de primer orden (Berrocal 1998; Ramallo \& Martínez 2010, 155; Cerezo 2016). Las últimas investigaciones en lo tocante a la topografía urbana de la ciudad en general y la portuaria en particular ponen de relieve un significativo proceso de remodelación urbanística que afectó a buena parte de los edificios públicos y privados de la ciudad en las postrimerías de época flavia y, especial-

2 CIL VI, 9766. 
mente, durante momentos trajaneo-adrianeos (Soler \& Noguera 2011, 1100, 1102; Romero 2015, 129). Obviamente, este proceso de monumentalización y refectiones que se desarrolla está en estrecha relación con un periodo económicamente favorable siendo el puerto el leitmotiv del mismo, al abrigo de un aumento del tráfico comercial desarrollado a raíz de las transformaciones y disposiciones trajaneas en lo tocante a la organización de navicularii, negotiatores, etc. y el fortalecimiento de la annona. En efecto, algunos autores han señalado la importancia que adquieren en estos momentos los materiales de procedencia bética en contextos portuarios, así como la existencia en el ambiente epigráfico de la ciudad, del interés de individuos béticos por este puerto durante el s. II d.C. (Ramallo \& Martínez 2010, 156), lo que ha sido puesto en relación con el impacto del sistema annonario y su transformación como puerto principal redistribuidor a una escala más local (Cerezo 2015, 26; 2016, 742).

Otro de los puertos de la ruta mediterránea que encierra un especial interés en el análisis que se presenta es Valentia; las investigaciones más recientes en su solar muestran una importante pujanza económica en la ciudad a fines del s. I e inicios del in d.C, con la dotación de edificios públicos monumentales, y un proceso de expansión urbana que viene asociada a un destacado volumen de materiales importados entre los que empiezan a destacar los envases de transporte béticos (Burriel, Rivera \& Serrano 2003, 132; Jiménez, Rivera \& Roselló 2014, 267). De ello se deduce una importante actividad comercial y económica para momentos trajaneos muy en relación con su posición como puerto de recalada en los viajes annonarios. Esta actividad viene representada, además de por un alto volumen de mercancías de importación béticas, por la existencia de innumerables infraestructuras de las que destaca, entre otras, un gran horreum abierto directamente al puerto fluvial en el barrio septentrional de la ciudad y construido en los primeros momentos del s. II (Rivera 2008, 34, 35; 2011, 222, 223).

La ciudad de Valentia mantiene significativas conexiones con ciudades béticas, caso de Onoba puerto de salida de los metalla del arco atlántico, como se comprueba de la existencia de un importante personaje onobense que fue sepultado en esta colonia; su inscripción honorífica ${ }^{3}$, hallada en 1960 reutilizada en la cubierta de una tumba del s. III d.C. en la necrópolis de la Boatella, destaca en su cursus honorum el desempeño de algún cargo de relevancia en la Provincia Ulterior Baetica (Corell 2009, 154, 155). La presencia de este incola en Valentia, un destacado personaje bético que desempeñó un cargo provincial (flamen, procurator?), puede corresponderse con la figura de un agente comercial que actuaría en este puerto mediterráneo. Sea como fuere, al igual que sucedía en el ambiente epigráfico de Cartagho Nova, la presencia de importantes individuos béticos revela el destacado papel que adquirieron estos puertos en sus intereses comerciales y económicos en el contexto de fines del s. I d.C.

Síntomas de un similar auge comercial y económico se documentan en el puerto de Tarraco. A día de hoy el conocimiento de sus infraestructuras, horrea, disposición, técnicas constructivas, etc., permite establecer con claridad una cierta evolución desde momentos republicanos hasta su progresiva transformación en momentos tardoantiguos, con especial interés en los momentos flavios e inmediatamente posteriores ${ }^{4}$, periodo en el que parece existir una importante transformación en la zona de los almacenes con un aumento significativo de los mismos (Pociña \& Remola 2001, 90 y ss.; Bea 2004, 237).

Adentrados ya en el Golfo de León, en las costas galas, se ubica un conjunto de puertos principales y stationes dependientes que conformaron los puntos de escala de parte de las rutas que trans-

3 CIL II2/14, 40.

${ }^{4}$ Sin duda, la publicación de la reciente Tesis doctoral «Portus Tarraconis. El puerto de Tarraco en época tardorrepublicana y altoimperial. Fuentes, historiografia y arqueologia», de la dra. P. Terrado, aportará interesantes datos a este respecto. 
portaban los productos annonarios. Uno de los primeros puntos de recalada lo constituía el puerto estuarino de Narbo, un centro administrativo y económico de primer orden en la zona gracias a su posición privilegiada como nodo comercial en el que se conectaban las rutas marítimas con las interiores. Considerado uno de los puertos más relevantes del mundo romano, el distrito marítimo y portuario de Narbo ha sido objeto de recientes investigaciones (Sanchez 2011; Sanchez \& Jézéguo 2011) en las cuales se ha puesto de relieve, mediante estudios arqueológicos y geomorfológicos, un importante conjunto de pequeños fondeaderos y stationes, Port-la-Nautique, St. Martin, etc., que irán evolucionando en un cambiante medio deltaico (Falguera et al. 2000; Ambert 2000; Cavero 2011). Este complejo portuario permitía el transbordo de mercancías a través de un sistema combinado de tráfico marítimo-fluvial en el que se aprecia para momentos de fines del s. I e inicios del s. II d.C. el rol tan destacado del puerto avanzado de Le Castelou en detrimento de Port-Le-Nautique (Cavero et al. 2010, 103, 104; Sanchez et al. 2011, 223). Esta reestructuración de ámbitos portuarios parece responder a una diversificación económica, así como probablemente a cuestiones geomorfológicas, en estrecha ligazón con la mayor presencia de productos hispanos en los mercados; en efecto, el registro material procedente de los puertos de abastecimiento béticos y tarraconenses es dominante en los registros hasta el s. III d.C. (Sanchez, Carrato \& Favennec 2011, 185, 199). Una imagen más precisa aporta el análisis de los sellos anfóricos olearios béticos de Narbo y Arelate, que testimonian un mayor porcentaje para aquellos correspondientes al imperio de Trajano (Garrote \& Marimon 2011, 238).

Todos estos datos deben ponerse en relación en el contexto del reforzamiento del sistema annonario bajo las medidas legales desarrolladas por Trajano. En efecto, a medida que nos situamos en este periodo histórico, se aprecia cómo el distrito portuario de Narbo pasará a centralizar, como capital provincial, la recepción del aceite bético para su posterior redistribución local, regional o interprovincial. Desde momentos de Trajano hubo una reconversión en las actividades comerciales del puerto y estos cambios estuvieron relacionados con la creciente importancia de los navicularii narbonenses y sus relaciones con el estado romano, los cuales dejan constancia de sus intereses para con la annona en la statio número 32 del pórtico de las corporaciones de Ostia (Garrote 2003, 228, 229; Coadic 2011, 95).

Similar proceso de repunte económico se aprecia en el emporio de Marsella, uno de los principales puertos de este litoral junto con los anteriormente descritos. En este enclave, donde se documentan excepcionales sistemas de atraque, en algún caso conformados por un imponente muelle de bloques pétreos (Sillano \& Weydert 2007, 76, 77), se constata la evolución geomorfológica y diacrónica de su puerto desde momentos helenísticos hasta el periodo romano. En el tránsito del s. I al ir d.C. se documenta un importante conjunto de horrea con dolia encastrados, entre otros tantos elementos, así como un muro que, a modo de escollera, restos de amarres, etc. permitían el atraque de embarcaciones; conjuntamente aparecieron diversos pecios que testimoniaban la actividad comercial para este momento (Guery 1992, 121). La hipótesis de partida plantea la existencia de un frente portuario de más de $150 \mathrm{~m}$. en torno al cual se disponían todas las infraestructuras portuarias (Hesnard 1994, 211, 212).

\section{CONSIDERACIONES FINALES: LA RELACiÓN CON EL TIRRENO}

En páginas precedentes se han indicado las principales medidas políticas desarrolladas por parte de Trajano con la clara intención de imprimir un nuevo ritmo en la economía y garantizar los suministros de productos vitales a sectores clave del estado, los mercados urbanos y el ejército, funda- 
mentalmente. La atención prestada por Trajano a estas medidas, cuyo ejemplo más visible hoy día es la magna construcción de su puerto en Portus, la reorganización de un complejo portuario en la costa del Tirreno (Centucellae, Terracina, Anzio) así como un conjunto de disposiciones legales tendentes al reforzamiento del abastecimiento de la annona y la creación de collegia, permite comprender, en este claro contexto, el desarrollo que experimentan un significativo conjunto de enclaves portuarios atlánticos y mediterráneos (fig. 2).

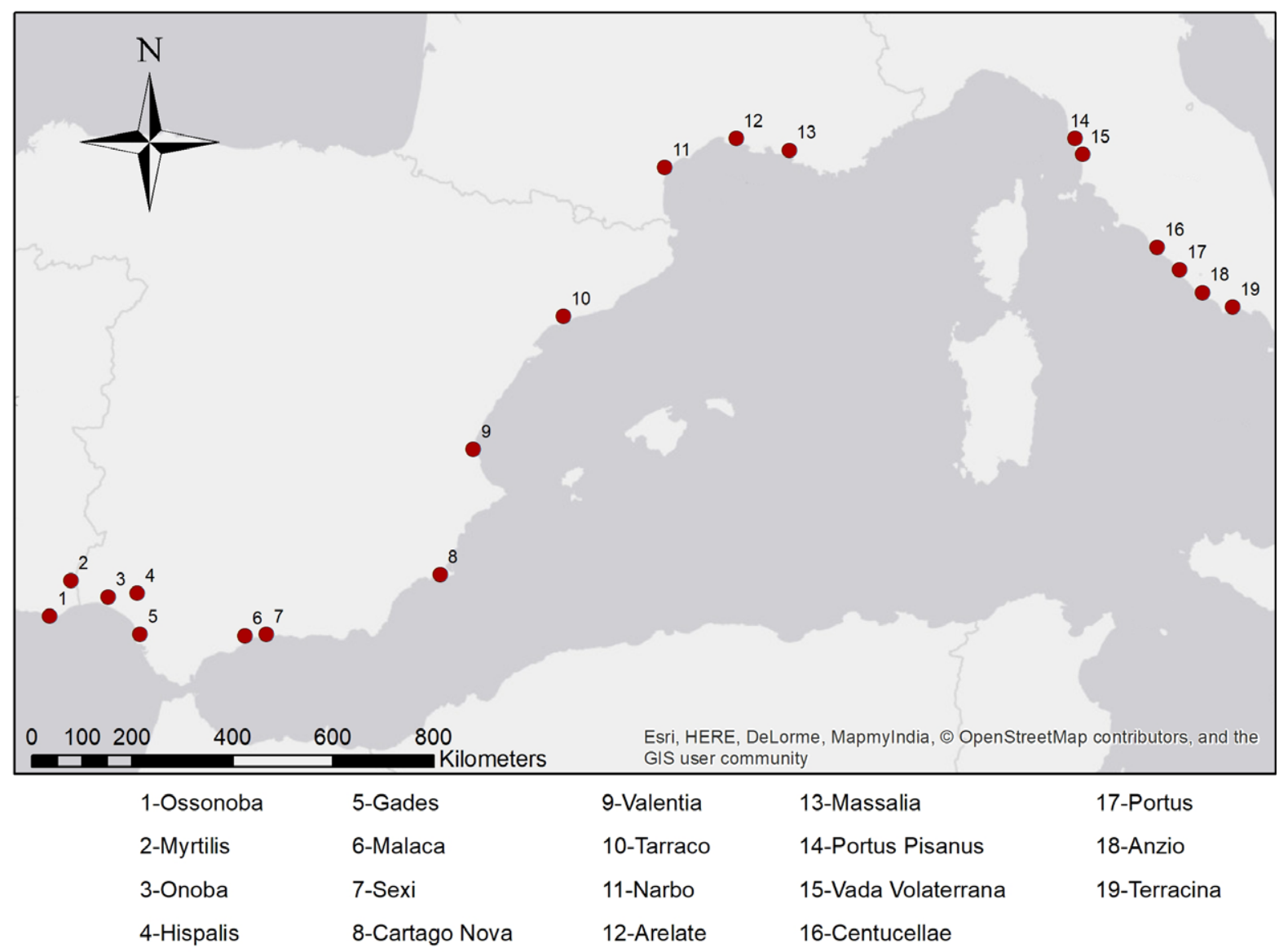

FigurA 2. Mapa con indicación de los puertos tratados en el trabajo.

Obviamente en este trabajo, dada las limitaciones de su extensión, han quedado fuera del mismo importantes enclaves que merecerían ser recogidos en ulteriores estudios de conjunto, como Carteia, Lucentum, Barcino, etc. No obstante, sirva este para posicionar, de manera introductoria, la significación que adquirieron determinados puertos mediterráneos y atlánticos en tiempos de Trajano.

En un claro diseńo estratégico, las rutas annonarias que partían de estos puertos tenían como claro destino comercial la costa tirrénica. Obviamente, la llegada de mercancías béticas y su presencia en los circuitos comerciales itálicos no es exclusiva de este periodo; sin embargo, a partir de mo- 
mentos trajaneos conocerán una especial proyección. Los restos de envases de los distritos marítimos de Liguria, así como del área interior, denotan la significación que adquieren en los mercados las importaciones de productos hispánicos, especialmente béticos, con una alta representación en los registros a partir de momentos de la segunda mitad del s. I d.C. y el tercer cuarto del II d.C. de envases tipo Dressel 2-4, 20, 7 -11 y Beltrán IIb (Gambaro \& Parodi 2016, 522 y ss.). De manera similar, para el área del ager Pisanus, al norte del Tirreno, se documenta una proyección gradual a lo largo del s. I y iI d.C. en los mercados de los productos hispánicos, especialmente referidos a las salsas de pescado y aceite béticos. El análisis del material anfórico en las áreas del territorio pisano-volterrano indica la importancia que adquieren las importaciones procedentes de la península ibérica. A medida que avanza el s. II las salsas y salazones de pescado bético inundan los circuitos comerciales tirrénicos con un protagonismo excepcional, al alcanzar importantes porcentajes los envases de transporte en los registros de horrea estudiados; así en puertos como Vada Volaterrana, Fiesole o Pistoia los porcentajes de ánforas salsarias, del total de productos béticos, suponen el 63, 75 y hasta 78 por ciento (Paschinucci \& Menchelli 2003, 242, 243).

Ya en el área lacial, en el ager Portuensis, el impacto de las medidas mencionadas en páginas precedentes referente al abastecimiento estatal llevará igualmente a una importante presencia de productos hispánicos y béticos en los circuitos comerciales, consecuencia de la importancia del tráfico annonario desde los puertos atlánticos y mediterráneos alcanzado en las postrimerías del s. I d.C., tal y como muestran los envases de transporte Dresel 20, 14 y Haltern 70 (Mele 2005, 226). La concepción de un nuevo puerto anexo al anterior de Claudio supone la culminación de un programa tendente al reforzamiento económico del estado, de las medidas desarrolladas en materia intervencionista que afectaban de manera directa al comercio y sus agentes.

La construcción de Portus Traiani Felicis es el reflejo de una imponente máquina estatal que necesita del abastecimiento constante y fluido para mantenerse en pie, Trajano supo ver dichas necesidades y logró fortalecer un conjunto de rutas comerciales que llevará parejo el desarrollo topográfico, económico y urbanístico de numerosos enclaves portuarios en la fachada atlántica y el mediterráneo occidental.

\section{BibLIOGRAFÍA}

Ambert, P., 2000, «Narbonne Antique et ses ports, Géomorphologie et Archéologie, Certitudes et hypothèses», Revue Archéologique de Narbonnaise 33, 295-307.

BEA, D., 2004, «El port romà de Tarraco, aportacions historiogràfiques i noves interpretacions. La intervenció arqueològica als solars de l'UA 15 de Tarragona (Tarragonès)", Tribuna d'Arqueologia (2004-2005), 215-243.

Bermejo, J., J. M. Campos \& S. Robles, 2013, «Trajano fundador, el último impulso colonizador del imperio", Onoba. Revista de Arqueología y Antigüedad 1, 99-114.

Bermejo, J., J. M. Campos \& J. Rodríguez-Vidal, 2017, «Las estructuras portuarias de Onoba Aestuaria: un puerto pesquero y de control imperial», en: J. M. Campos, J. Bermejo (eds.), Los puertos atlánticos béticos y lusitanos y su relación comercial con Ostia Antica [Hispania Antigua. Serie Arqueológica 7], Roma: L'Erma di Bretschneider, 207-244.

Bernal, D., 2012, "El puerto romano de Gades. Novedades arqueológicas», en S. Keay (ed.), Rome, Portus and the Mediterranean [Archaeological Monographs of the British School at Rome] Vol., 21, Londres, 225-244.

Bernal, D., A. Arévalo, J. J. Díaz, J. Lagóstena, J. M. Vargas, M. lara, A. M. Sáez, M. BustamanteÁlvarez, J. A. Expósito \& A. Muñoz, 2013, «Las termas y el suburbium marítimo de Baelo Claudia. Avance de un reciente descubrimiento", Onoba. Revista de Arqueología y Antigüedad 1, 115-152. 
Bernal, D., J. A. Expósito, J. J. Díaz, N. Carayon, K. Strutt, F. Salomon \& S. Keay, 2017, «Baelo Claudia, puerto pesquero, comercial y de viajeros. Nuevas perspectivas», en: J. M. Campos, J. Bermejo (eds.), Los puertos atlánticos béticos y lusitanos y su relación comercial con Ostia Antica [Hispania Antigua. Serie Arqueológica 7], Roma: L'Erma di Bretschneider, 307-346.

Bernal, D., \& M., Lara, 2012, «Desenterrando a Gades. Hitos de la arqueología preventiva, mirando al futuro», en: J. Beltrán, O. Rodríguez (coords.), Hispaniae Vrbes. Investigaciones arqueológicas en ciudades históricas, Sevilla, 423-473.

Bernal, D., A. M. Sáez, R. Montero, J. J. Díaz, A. Sáez, D. Moreno \& E. Toboso, 2005, «Instalaciones fluvio-marítimas de drenaje con ánforas romanas: a propósito del embarcadero flavio del caño de Santi Petri (San Fernando, Cádiz)», Spal 14, 179-230.

Bernardes, J. P., 2005, «Morrer em Faro há 2000 anos - as Necrópoles de Ossonoba», en: Caminhos do Algarve Romano / Paths of the Roman Algarve (Catálogo da Sala Lapidar do Museu Municipal de Faro), Faro: Museu Municipal de Faro, 26-34.

—, 2012, "A cidade de Ossonoba e o seu territorio», Anais do Município de Faro, XXXVII, Faro, 11-26.

—, 2017, "O sistema portuário de Ossonoba», en: J. M. Campos, J. Bermejo (eds.), Los puertos atlánticos béticos y lusitanos y su relación comercial con Ostia Antica [Hispania Antigua. Serie Arqueológica 7], Roma: L'Erma di Bretschneider, 379-398.

Berrocal, M. a C., 1998, «Instalaciones portuarias en Carthago Nova: la evidencia arqueológica», III Jornadas de arqueología subacuática: puertos antiguos y comercio maritimo, 99-114.

Buriel, J., A. Ribera \& M. L. Serrano 2003, «Un área portuaria al norte de Valentia», en: G. Pascual, J. Pérez (eds.), Puertos fluviales antiguos, ciudad, desarrollo. Actas IV Jornadas de arqueología subacuática, 127-142.

Cabrera, C., 2016, From Hispalis to Ishbiliyya: the ancient port of Seville, from the Roman Empire to the end of the Islamic period ( 45 BC-AD 1248), tesis doctoral inédita, Universidad de Oxford.

Campos, J. M., 2011, Onoba Aestuaria. Una ciudad portuaria en los confines de la Baetica, Huelva.

—, 1990, «Estructura urbana de la Colonia Iulia Romula Hispalis en época republicana», Habis 20, 245-262.

—, 1993, «La estructura urbana de la Colonia Iulia Romula Hispalis en época imperial», AAC 4, 181-219.

Campos, J. M., \& J. Bermejo, 2017, «Del Atlántico al Tirreno. Los puertos atlánticos béticos y lusitanos y su relación comercial con Ostia Antica», en: J. M. Campos, J. Bermejo (eds.), Los puertos atlánticos béticos y lusitanos y su relación comercial con Ostia Antica [Hispania Antigua. Serie Arqueológica 7], Roma: L'Erma di Bretschneider, 207-244.

—, 2017 (eds.), Los puertos atlánticos béticos y lusitanos y su relación comercial con Ostia Antica [Hispania Antigua. Serie Arqueológica 7], Roma: L'Erma di Bretschneider.

Campos, J. M., \& J. González, 1987, «Los foros de Hispalis Colonia Romula», AEA 60, 123-158.

Cavero, J., 2011, «Narbonne: historiographie et topographie des découvertes archéologiques relatives au système portuaire», en: C. Sanchez, M. P. Jézégou, Zones portuaires et espaces littoraux de Narbonne et sa région dans l'Antiquité, Monographie d'Archéologie Méditerranéenne 28, 25-34.

Cavero J., M. Druez, M. Guy, M.-P. Jézégou, V. Mathe \& C. Sanchez, 2010, «Un exemple d'approche pluridisciplinaire pour la compréhension des aménagements portuaires de Narbonne antique», en: X. Delestre, H. Marchesi (eds.), Archéologie des rivages méditerranéens: 50 ans de recherche. Actes du colloque d'Arles (Bouches-du-Rhône) 28-29-30 octobre 2009, éditions Errance/Ministère de la Culture et de la Communication, Arles, 99-106.

Cerezo, F., 2015, «El puerto de Cartago Nova. Tráfico marítimo a través de los contextos materiales de época augustea», II Congrés Internacional d'Arqueologia i Món Antic Tarraco Biennal 2014 vol. II, 23-33.

—, 2016, Los puertos antiguos de Cartagena: geoarqueología, arqueologia portuaria y paisaje marítimo: un estudio desde la arqueología náutica. Universidad de Murcia.

Chic, G., 2000, «Trajano y el arte de comerciar», en Trajano. Emperador de Roma. Congreso Internacional. Trajano, Emperador de Roma. Roma: L'Erma Di Bretschneider, 71-101.

—, 1999, "Comercio e intercambio en la Hispania romana», Studia Historica. Historia Antigua 17, 243262. 
CoAdic, S., 2011, «La question de l'allègement des navires de haute mer: la mosaïque des Narbonnais à Ostie», en: C. Sanchez, M. P. Jézégou (eds.), Zones portuaires et espaces littoraux de Narbonne et sa région dans l'Antiquité, Monographie d'Archéologie Méditerranéenne, 28, 95-100.

Corell, J., 2009, Inscripcions romanes del País Valencià, V: Valentia i el seu territori, Valencia.

Corrales, A., 2008, «El litoral malacitano y el mar de Alborán, una intensa relación económica en época romana", Mainake XXX, 157-180.

Delgado, S., 2016, Onoba Aestuaria, Universidad de Huelva.

Eск, W., 2002, «An Emperor is made: Senatorial Politics and Trajan's Adoption by Nerva in 97», Philosophy and Power in the Graeco-Roman World: Essays in Honour of Miriam Griff, 211-226.

Falguéra, J. M., F. Falguéra, M. Guy \& A. Marsal, 2000, «Narbonne: cadre naturel et ports à l'époque romaine", Méditerranée 94, 1-2, 15-24.

Gambaro, L., \& A. Parodi, 2016, "Amphorae ex Hispania nella Liguria di Ponente nel corso della prima e media età imperiale», en: R. Járrega, P. Berni (eds.), Amphorae ex Hispania: paisajes de producción y consumo, Monografias Ex Officina Hispana III, III Congreso Internacional de la Sociedad de Estudios de la Cerámica Antigua (SECAH) - Ex Officina Hispana (Tarragona, 10-13 de diciembre de 2014), 516-529.

García, E., \& F. Chaves, 1991, «Reflexiones en torno al área comercial de Gades. Estudio numismático y económico", Gerión no extra 3, 139-168.

García, E., S. Ordóñez \& C. Cabrera, 2017, «El puerto romano de Hispalis. Panorama arqueológico actual», en: J. M. Campos, J. Bermejo (eds.), Los puertos atlánticos béticos y lusitanos y su relación comercial con Ostia Antica [Hispania Antigua. Serie Arqueológica 7], Roma: L'Erma di Bretschneider, 245-286.

Garrote, E., 2003, «Los puertos de Narbo Martius y Arelate y su relación con los circuitos comerciales del aceite bético», en: G. Pascual, J. Pérez (eds.), Puertos fluviales antiguos, ciudad, desarrollo. Actas IV Jornadas de arqueología subacuática, 227-236.

Garrote, E., \& P. Marimon, 2011, "Nouvelles données sur l'huile de Bétique en Narbonnaise», en: C. Sanchez, M. P. Jézégou (eds.), Zones portuaires et espaces littoraux de Narbonne et sa région dans l'Antiquité, Monographie d'Archéologie Méditerranéenne, 28, 237-244.

González, D., 2010, "Hispalis, puerto romano de la Bética. Aproximación urbanística», Bollettino di Archeologia on line. Volume speciale, 83-111.

—, 2011, Forma Urbis Hispalensis: el urbanismo de la ciudad romana de Hispalis a través de los testimonios arqueológicos, Sevilla.

—, 2012, «Planificación y gestión urbana en Hispalis», en J. Beltrán, O. Rodríguez (coords.), Hispaniae Urbes. Investigaciones arqueológicas en ciudades históricas, Sevilla, 859-880.

GonzÁlez, J., 2013, «Arqueología y paisaje urbano: las inscripciones de la Colonia Romula», en: J. M. Iglesias, A. Ruiz (eds.), Paisajes epigráficos de la Hispania romana monumentos, contextos, topografías [Hispania Antigua. Serie Historica, 9], Roma: L’Erma di Bretschneider, 57-68.

—, 2017, "La presencia de magistrados imperiales y subalternos en la epigrafía de Hispalis Colonia Romula», en: J. M. Campos, J. Bermejo (eds.), Los puertos atlánticos béticos y lusitanos y su relación comercial con Ostia Antica [Hispania Antigua. Serie Arqueológica 7], Roma: L’Erma di Bretschneider, 287-305.

Guery, R., 1992, «Le port antique de Marseille», en: M. Bats, G. Bertucchi, G. Congès, H. Tréziny (dirs.), Marseille grecque et la Gaule, Actes du Colloque international d'Histoire et d'Archéologie et du ve Congrès archéologique de Gaule méridionale (Marseille, 18-23 novembre 1990), Lattes / Aix-en-Provence, 109-122.

Hesnard, M. A., 1994, "Une nouvelle fouille du port de Marseille, place Jules-Verne», en Comptes rendus des séances de l'Académie des Inscriptions et Belles-Lettres, $138^{e}$ année 1, 195-217.

Jiménez, J. L., A. Ribera \& M. Roselló, 2014, «Valentia y su territorium desde época romana imperial a la antigüedad tardía: una síntesis», en: D. Vaquerizo, J. A. Garriguet, A. León (eds.), Monografías de Arqueología Cordobesa, 20, Ciudad y territorio: transformaciones materiales e ideológicas entre la época clásica y el Altomedioevo, 265-282.

Keay, S., 2012 (ed.), Rome, Portus and the Mediterranean [Series: Archaeological Monographs of the British School at Rome]. Vol. 21, London. 
Keay, S., \& M. Millet, 2005, «Integration and discussion», en: Portus: An Archaeological Survey of the Port of Imperial Rome [Archaeological Monographs of the British School at Rome,], Roma, 269-296.

Keay, S., M. Millet, L. Parodi \& K. Strutt, 2005, Portus: an Archaeological Survey of the Port of Imperial Rome [Archaeological Monographs of the British School at Rome,], Roma.

Lopes, V., 2014, Mértola y su territorio en la antigüedad tardía (s.s. IV-VIII), Universidad de Huelva.

—, 2017, «A cidade portuária de Mértola no período Romano e na Antiguidade Tardia», en: J. M. Campos, J. Bermejo (eds.), Los puertos atlánticos béticos y lusitanos y su relación comercial con Ostia Antica [Hispania Antigua. Serie Arqueológica 7], Roma: L'Erma di Bretschneider, 347-378.

Mele, C., 2005, "Amphorae», en: Portus: an Archaeological Survey of the Port of Imperial Rome [Archaeological Monographs of the British School at Rome,], Roma, 223-234.

Montero, S., 1955, «El Estado universal de Trajano», Estudios Clásicos 14, III, 10-24.

Niveau, A. M., 2015, «La estructuración del espacio urbano y productivo de Gadir durante la Fase Urbana Clásica: cambios y perduraciones», Complutum 26 (1), 225-242.

Pasquinucci, M., \& S. Menchelli, 2003, «Porti, approdi e dinamiche commerciali nell'ager Pisanus e nella valle dell'Arno (III sec. a.C.-VI sec. d.C.)», en: G. Pascual, J. Pérez (eds.), Puertos fluviales antiguos, ciudad, desarrollo. Actas IV Jornadas de arqueología subacuática, 237-250.

Pociña, C. A., \& J. A. Remola, 2001, «Nuevas aportaciones al conocimiento del puerto de Tarraco (Hispania Tarraconensis)", Saguntum. Papeles del Laboratorio de Arqueología de Valencia 33, 85-96.

Ponsich, M. 1968, "Alfarerías de época fenicia y púnico-mauritana en Kuass (Arcila, Marruecos)», Saguntum. Papeles del Laboratorio de Arqueología de Valencia 4, 3-25.

Ramallo, S. F., \& M. Martínez, 2010, «El puerto de Carthago Nova: Eje de vertebración de la actividad comercial en el sureste de la Península Ibérica», XVII International Congress of Classical Archaeology Meetings between Cultures in the ancient Mediterranean - 2008, vol. 1. Bollettino di Archeologia on line, 141-159.

Remesal, J., 2011, «Producción y comercio del aceitte y vino y las salazones en la España romana», en: J. M. Blázquez Martínez (coord.), Historia económica de España en la Antigüedad, Real Academia de la Historia, Madrid, 193-234.

Ribera, A., 2008, «Puertos y arquitectura comercial en la valencia antigua: Los orígenes de una larga tradición", Historia de la ciudad. V: Tradición y progreso, 29-39.

—, 2011, "Los horrea de Valentia, de la República al Imperio», en: J. Arce, G. Goffaux (eds.), Horrea d'Hispanie et de la Medtierranée romaine, Collection de la Casa de Velázquez (125), 201-223.

Rickman, G. E., 1991, «Problems of transport and development of ports», en A. Giovannini (ed.), Nourrir la plèbe, Bassel / Kassel, 103-115.

Romera, D., 2012, "Carthago Nova en el siglo II d.C.: una aproximación a su imagen urbana», Oppidum $11,127-142$.

Ruiz D., \& C. J. Pérez, 1995, El poblado fenicio del Castillo de Doña Blanca (El Puerto de Santa María, Cádiz), Cádiz.

Sáez, A. M., R. Belizón \& F. Carrero, 2017, «Primeras evidencias de un nuevo yacimiento púnico y romano en San Fernando (Cádiz)», Boletín Ex Officina Hispana 8, 12-16.

Sanchez, C. (coord.), 2011, Projet collectif de recherche sur les ports antiques de narbonne (Aude). Les ports antiques de narbonne, Vol. I.

Sanchez, C., C. Carrato \& B. Favennec, 2011, «Recherches récentes sur les contextes portuaires de Narbonne (Aude): les fouilles du Grand Castélou et de Port-la-Nautique», avec la col. de S. Lemaître et S. Silvéréano, SFECAG. Actes du Congrès d'Arles, 171-201.

Sanchez C., J. Cavero \& M.-P. Jézégou, G. Pagès, 2011, "Narbonne, la ville et ses ports», en: M. Pasqualini (textes réunis par), Fréjus romaine, la ville et son territoire. Les agglomérations de Narbonnaise, des Alpes-Maritimes et de Cisalpine à travers la recherche archéologique, 8e colloque historique, 8-10 octobre 2010, Fréjus, 153-166.

SAnchez, C., \& M. P. JÉzÉGou (eds.), 2011, Zones portuaires et espaces littoraux de Narbonne et sa région dans l'Antiquité, Monographie d'Archéologie Méditerranéenne, 28, Lattes. 
Sillano, B., \& N. Weydert, 2007, «Structures portuaries antiques à Marseille», Archéopages 19, Institut National de Recherches Archéologiques, 76-77.

Sirk, B. J., 1991, Food for Rome. The legal structure of the transportation and processing of supplies for the imperial distributions in Rome and Constantinople, Amsterdam.

Soler, B., \& J. M. Noguera, 2011, "Urban development and monumentalisation in the roman colony Vrbs Iulia Nova Karthago (Cartagena, Hispania Citerior)», Roma y las provincias: modelo y difusión II [Hispania Antigua, Serie Arqueolígica], Roma: L’Erma di Bretschneider, 1095-1105.

Teichner, F., 2017, "Cerro da Vila: A rural commercial harbour beyond the Pillars of Hercules», en: J. M. Campos, J. Bermejo (eds.), Los puertos atlánticos béticos y lusitanos y su relación comercial con Ostia Antica [Hispania Antigua. Serie Arqueológica 7], Roma: L’Erma di Bretschneider, 399-434. 